ScIDice

\section{Awareness And Knowledge About Temporomandibular Joint Problems During Bruxism In South Indian Population}

Research Article

Vignesh $\mathrm{P}^{1}$, Keerthi Sasanka Lakkoji², Venkatesh Kommi ${ }^{3 *}$, M.P. Brundha ${ }^{4}$

${ }^{1}$ Department of Prosthodontics, Saveetha Dental College and Hospital, Saveetha Institute of Medical and Technical Sciences Saveetha University, Chennai, India.

${ }^{2}$ Associate Professor, Department of Prosthodontics, Saveetha Dental College and Hospital, Saveetha institute of medical and technical sciences (SIMATS), Saveetha University, Chennai, India.

${ }^{3}$ Senior Lecturer, Department of Prosthodontics, Saveetha Dental College and Hospital Saveetha institute of medical and technical sciences Saveetha University, Chennai, India.

${ }^{4}$ Associate Professor, Department of General Pathology, Saveetha Dental College and Hospital Saveetha institute of medical and technical sciences Saveetha University, Chennai, India.

\title{
Abstract
}

The aim of the survey study is to create awareness and knowledge among people about Temporomandibular Joint during Bruxism in the South Indian population. A questionnaire of about 14 questions about Bruxism and TMJ and Circulated among dental students, the data are collected using google forms, and further SPSS is used for the statistical tests. Knowledge and awareness are created among the people and by seeing the data's about half of the people are already aware of various Temporomandibular joint disorders and Bruxism.

\section{Introduction}

Tooth grinding is an activity particularly important to the dentist due to the breakage of dental restoration, tooth damage, induction of temporal headache, and temporomandibular joint [21]. The prevalence of Bruxism in the general population is about $8 \%$ to $31 \%$ [24].

There are two main Kinds of of Bruxism: one occurs during sleep (nocturnal Bruxism) and one during Wakefulness ( awake Bruxism). The course of Bruxism is not completely understood but probably involves multiple factors [8]. Nocturnal Bruxism is a repetitive sleep movement disorder primarily characterized by rhythmic masticatory muscle activity and by occasional tooth grinding and is associated with brief cardiac and brain reactivation [5]. Awake Bruxism is characterized by only clenching-type. activity and is associated with psychosocial factors [23]. Early diagnosis of Bruxism is advantageous, but difficult Early diagnosis can prevent damage that may be in cursed and the detrimental effect on quality [29]. A diagnosis of Bruxism is usually made and is mainly based on the patient's history (eg. reports of grinding notes) and the presence of typical signs and symptoms including tooth mobility, tooth wear, masseteric hypertrophy, an indentation on the tongues, hypersensitive teeth (which may be misdiagnosed as reversible pulpitis), [2] Pain in the muscle of mastication and clicking or locking of the temporomandibular joint [27]. Even though Bruxism as a whole is commonly considered the most harmful parafunctional activity of the temporomandibular joint [TMJ] there are many unsolved Issues concerning the actual causes relationship between Bruxism and temporomandibular disorder $[16,13]$. The main uncertainties are due to a lack of knowledge on the etiology and diagnosis of Bruxism [12]. andTemporomandibular disorder [23]. Damage to the articular disc can be a cause of TMD Some researches have shown [18] have shown that acute mechanical overload in Invivo Can come severe cartilage damage this $[26,32]$.

\section{Materials And Method}

A questionnaire of about 14 questions is Prepared about understanding the Bruxism and Temporomandibular joint, Tem-

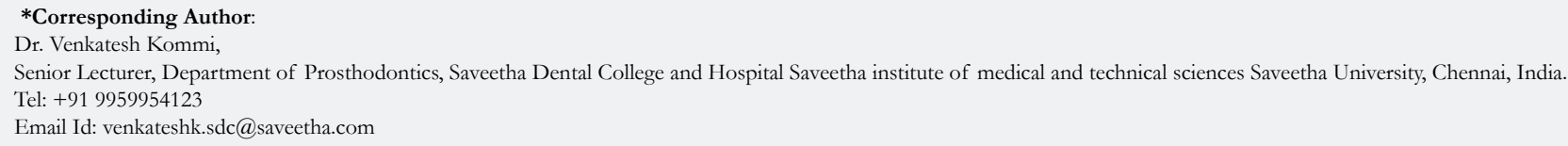

Copyright: Venkatesh Kommi $^{\circ} 2021$. This is an open-access article distributed under the terms of the Creative Commons Attribution License, which permits unrestricted use, distribution and reproduction in any medium, provided the original author and source are credited. 
peromandibulandiar disorders, and other Bruxism associated Neurological and psychiatric disorders. (Table 1) [28] Further, the Questionnaire is circulated among The people through online platforms (google form) and responses are Collected. The sample size is 100 people who Reside among the south Indian population. The response is collected and viewed in an excel sheet and further analyzed using IBM SPSS software and tabulated. (Ganapathyet al., 2016).

\section{Results And Discussion}

The first goal of the research article is to create awareness and knowledge about Bruxism, Temporomandibular disorder, treatments as a result of the survey various questions are answered and it will be explained briefly [31].

As the data are collected and depicted as a pie chart. This questionnaire based Survey study has given knowledge and awareness about Bruxism, Temporomandibular joint, and associated disorders [2]. Our sample population was about 100 in number. In Figure 2 shows that most of the people are already aware of the term Bruxism like $76 \%$ of the people said the Bruxism means Clenching or grinding of the teeth and $18 \%$ of them said that it means Biting fingernail and remaining $6 \%$ of them said biting lips [33]. In Figure 3 shows that the major Cause of Bruxism is stress and anxiety [34]. While in previous studies $86 \%$ of Bruxism episodes are associated with arousal response along with involuntary leg movement. (Lavigneet al., 2008) [21] Figure 4 shows that about 90 people are aware the Bruxism is dangerous if it occurs regularly Figure 5 shows that $82 \%$ of the people said that Bruxism is a habit and $18 \%$ of them said no according to the previous studies is it proved that Bruxism is defined as an unconscious habit of rhythmical unfunctional clenching [10] In figure 6, According to the response $46 \%$ of them said that symptoms of bruxism are facial pain, headache, and earache and $28 \%$ of them said only facial pain $16 \%$ of them said only headaches and $10 \%$ of them said the only earache [6] And in Figure 7 About $72 \%$ of the people said that night guards are good for temporomandibular disorder and $28 \%$ of the people said no it does not [1]. According to our study, (Figure 8 ) most of them said that Bruxism occurs during Stage 5 $[R E M\}][4,15]$. but previous research has suggested that $80 \%$ of the Bruxism in young adult occurs in Stage 1 and 2 and is about $5-10 \%$ during REM $[35,36]$ In Figure 9 it shows that About 73\% of them said that Bruxism causes Temporomandibular disorders while according to one previous study it is concluded that about $50 \%$ of the population TMJ disorders are due to Bruxism [9]. If TMJ Disorders is left untreated the majority (Figure 10) $73 \%$ of them said it causes enamel erosion, fractured teeth, mobility, gum recession, flattening of the chewing surface, and more $23 \%$ of them said that it causes sinus problems and remaining $4 \%$ of them said body pain $[11,30]$ In Figure 11 people responded that About $52 \%$ of them said nocturnal Bruxism means that it occurs while awake $48 \%$ of them said that it occurs while sleeping [4].

In our study, $80 \%$ of them said that Bruxism will go away and $20 \%$ of them said it will will not go away( Figure 12) but previous studies have concluded that Bruxism will not go away by itself [25] In figure 15 it shows that According to our study, about $46 \%$ of them have Bruxism and remaining $54 \%$ of them do not have Bruxism, previous studies report that $22 \%$ of the population have Bruxism [20].

A gender comparison was done on awareness of causes, dangerous effects, habituality, symptoms and signs and prevention methods (Figure 16-20). It was found that there was statistically non significant difference between the awareness among the males and females in this study. The study by (Berger et al., 2016) [7], also had similar results and was well correlated with this study.

\section{Conclusion}

In the absence of awareness treatment and management of Bruxism focus to prevent progression of dental wear, reduce. teeth Grinding sounds, and improve muscle discomfort and mandib-

Figure 1. The pie chart shows the percentage of responses given by participants of about gender about $58 \%(\mathrm{Blue})$ of them are male, $42 \%$ (red) of them are female.

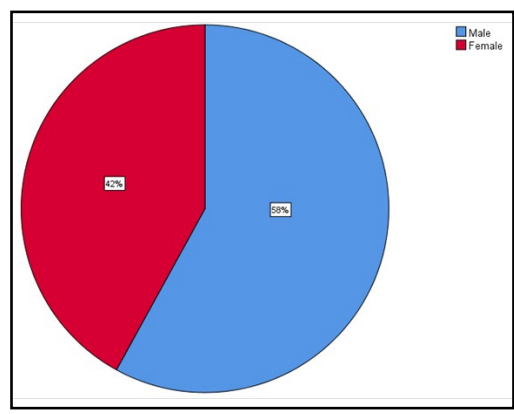

Figure 2. The pie chart shows the percentage of responses given by participants of about awareness of Bruxism about $71 \%$ (Blue) of the people said the Bruxism means Clenching or grinding of the teeth and 23\% (red) of them said that it means Biting fingernail and remaining $6 \%$ (green)of them said biting lips.

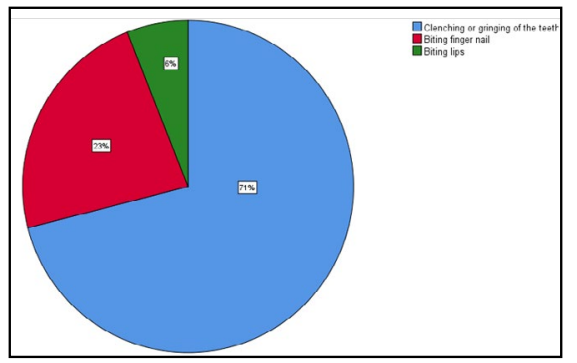


Figure 3. The pie chart shows the percentage of responses given by participants of about causes of Bruxism about $57 \%$ (Blue) of the people said that the cause of Bruxism is Stress and Anxiety and 25\% (red) of them said that it is some neurological issue and the remaining $18 \%$ (green) of them don't know.

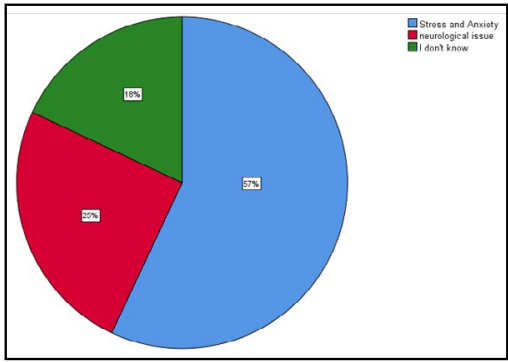

Figure 4. The pie chart shows the percentage of responses given by participants when asked is Bruxism dangerous about $\mathbf{9 0 \%}$ (Blue) of the said Bruxism is dangerous if it occurs regularly and the remaining $10 \%$ (red) of them said it's not dangerous.

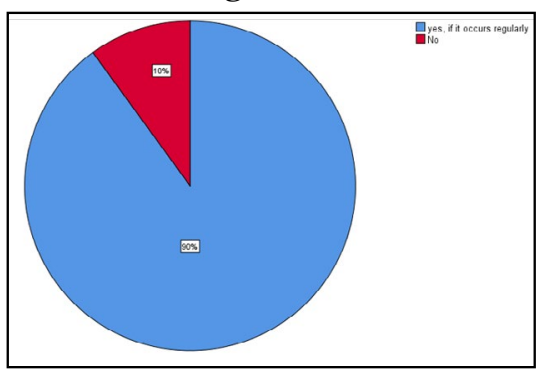

Figure 5. The pie chart shows the percentage of responses given by participants of when asked is Bruxism a Habit about $82 \%$ (Blue) of the people said that Bruxism is a habit and $18 \%$ (red) of them said no.

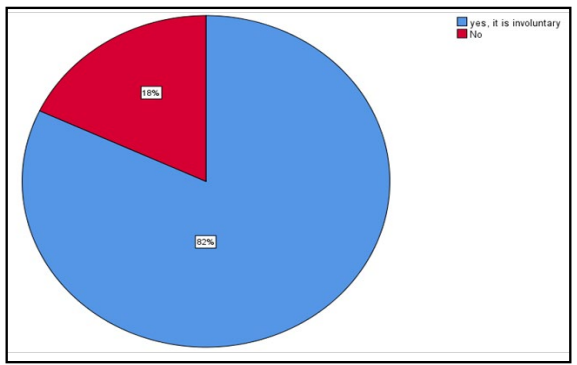

Figure 6. The pie chart shows the percentage of responses given by participants about symptoms about $46 \%$ (orange) of them said that symptoms of bruxism are facial pain, headache, and earache and $28 \%$ (Blue) of them said only facial pain $16 \%$ (red) of them said only headaches and $10 \%$ (green) of them said the only earache.

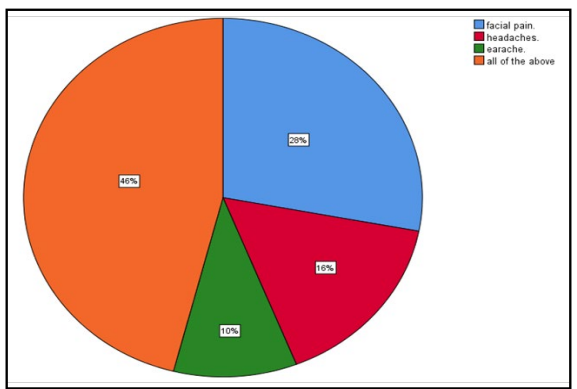

Figure 7. The pie chart shows the percentage of responses given by participants about night guards about $72 \%$ (Blue) of the people said that night guards are good for temporomandibular disorder and $28 \%$ (red)of the people said no it does not.

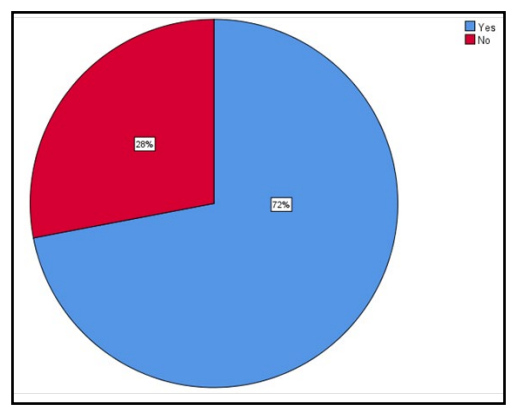


Figure 8. The pie chart shows the percentage of responses given by participants about sleep stages about $22 \%$ (Blue) of them said stage $3,38 \%$ (red) of them said stage $4,40 \%$ (green) of them said stage 5 .

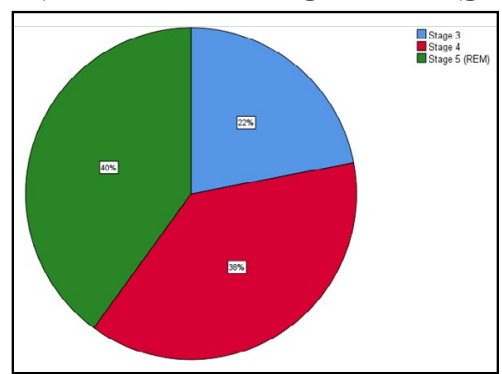

Figure 9. The pie chart shows the percentage of responses given by participants about cause of TMJ disorders, about $73 \%$ (blue) of them said that Bruxism causes Temporomandibular disorders and 27\% (red) of them said that Bruxism does not causes Temporomandibular disorders .

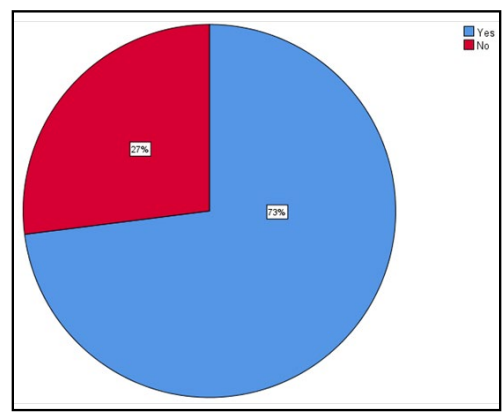

Figure 10. The pie chart shows the percentage of responses given by participants about untreated TMJ disorders, about $73 \%$ (Blue) of them said it causes enamel erosion, fractured teeth, mobility, gum recession, flattening of the chewing surface, and more $23 \%$ (red) of them said that it causes sinus problems and remaining $4 \%$ (green) of them said body pain.

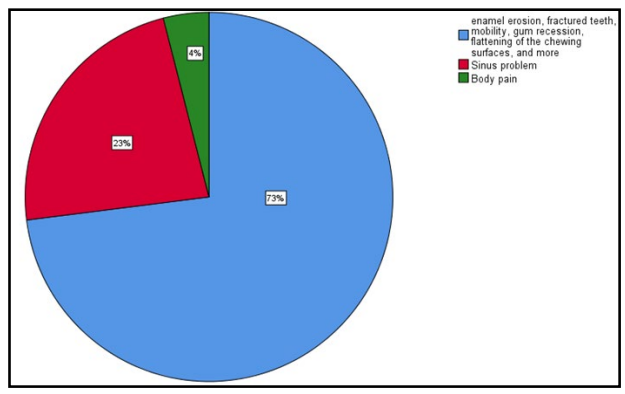

Figure 11. The pie chart shows the percentage of responses given by participants about nocturnal Bruxism, About $52 \%$ (Blue) of them said nocturnal Bruxism means that it occurs while awake $48 \%$ (red) of them said that it occurs while sleeping.

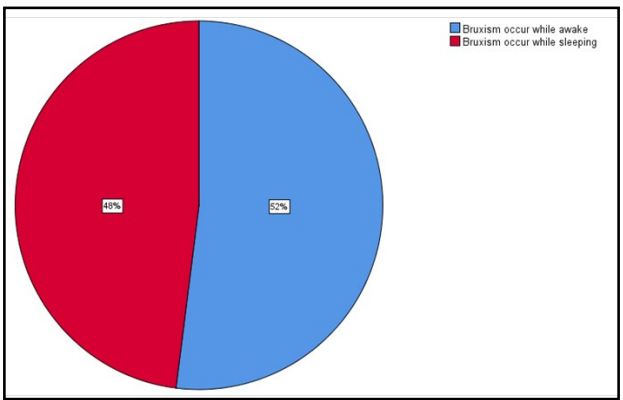

Figure 12. The pie chart shows the percentage of responses given by participants when asked can Bruxism go away, about $80 \%$ (Blue) of them said that Bruxism will go away and $20 \%$ (red) of them said it will not go away.

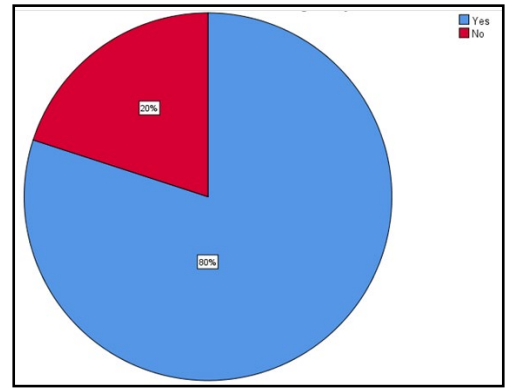


Figure 13. The pie chart shows the percentage of responses given by participants about treatment, about $65 \%$ (blue) of them said that the treatment for Bruxism is muscle relaxant and $27 \%$ (red) of them said NSAID, $8 \%$ (green) of them said meditation.

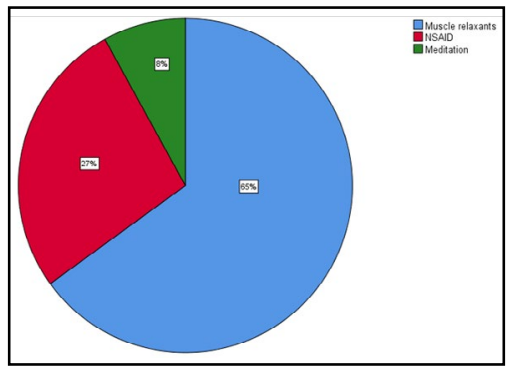

Figure 14. The pie chart shows the percentage of responses given by participants about symptoms, about $61 \%$ (Blue) of the people said that Bruxism is a symptom of sleep apnea and the remaining $39 \%$ (red) of them said it not a symptom of sleep apnea.

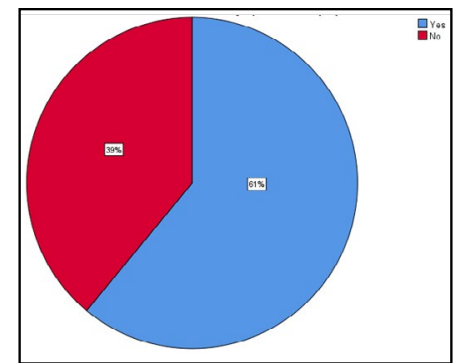

Figure 15. The pie chart shows the percentage of responses given by participants when asked do you have Bruxism about $46 \%$ (Blue) of them have Bruxism and remaining 54\% (red) of them do not have Bruxism.

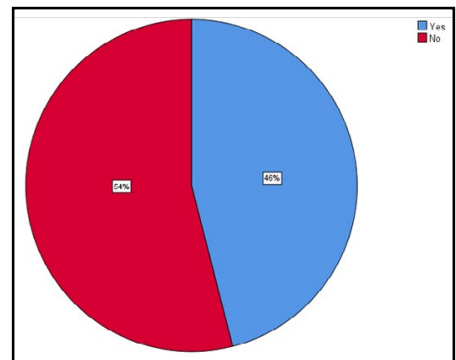

Figure 16. Bar graph shows the comparison of Gender about causes. $\mathrm{X}$ axis represents the Gender of the responded population and $\mathrm{Y}$ axis represents the various causes like stress and anxiety (blue), neurological issue (red), don't know (green) which was responded to by the population. Most of them said stress and anxiety are the main causes of Bruxism. Pearsons's Chi square value- 0.193 , $\mathrm{p}$ value $=0.908(>0.05)$ hence not significant.

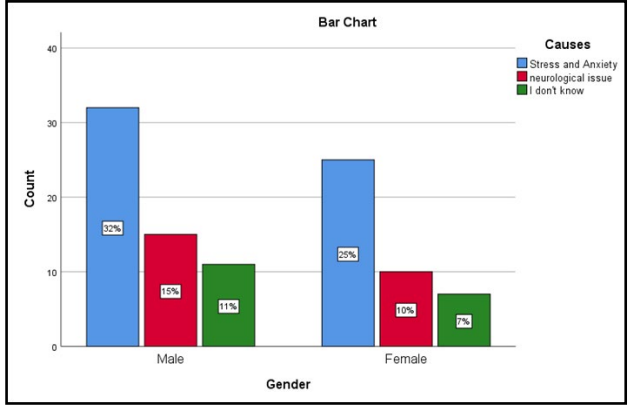

Figure 17. Graph shows the correlation between Gender and dangerous $\mathrm{X}$ axis represents the Gender of the responded population and $\mathrm{Y}$ axis represents whether it is dangerous(blue) or not(red). More male population said that Bruxism is dangerous if it occurs regularly than females. Pearsons's Chi square value- $0.018, \mathrm{p}$ value $=0.893(>0.05)$ hence not significant.

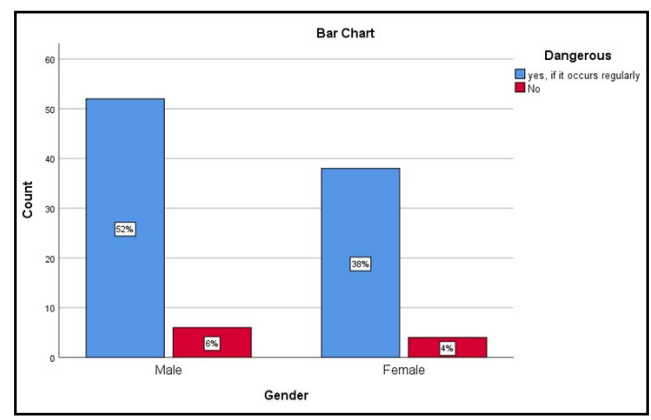


Figure 18. Graph shows the correlation between Gender and Habit. X axis represents the Gender of the responded population and $\mathrm{Y}$ axis represents whether it is habit(blue) or not(red) . More male population said that Bruxism is an involuntary habit than females. Pearsons's Chi square value- 0.087, $\mathrm{p}$ value $=0.768(>0.05)$ hence not significant.

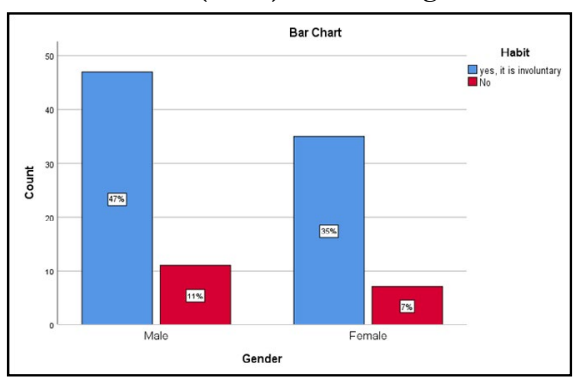

Figure 19. Graph shows the correlation between Gender and guards for TMJ reveals p value $=0.576$ which is not significant. $\mathrm{X}$ axis represents the Gender of the responded population and $\mathrm{Y}$ axis represents whether night guards are good(blue) or not(red). More male population said that night guards are good for Bruxism than females. Pearsons's Chi square value- 0.313 , p value $=0.576(>0.05)$ hence not significant.

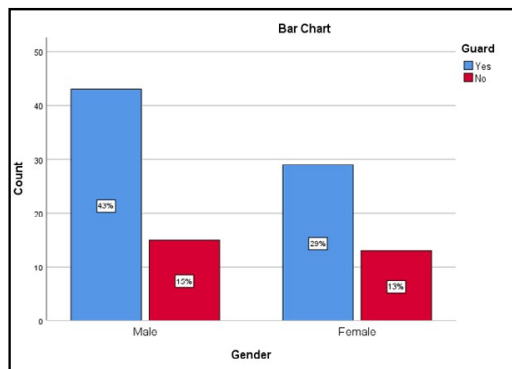

Table 1. Questionnaire Used In The Study.

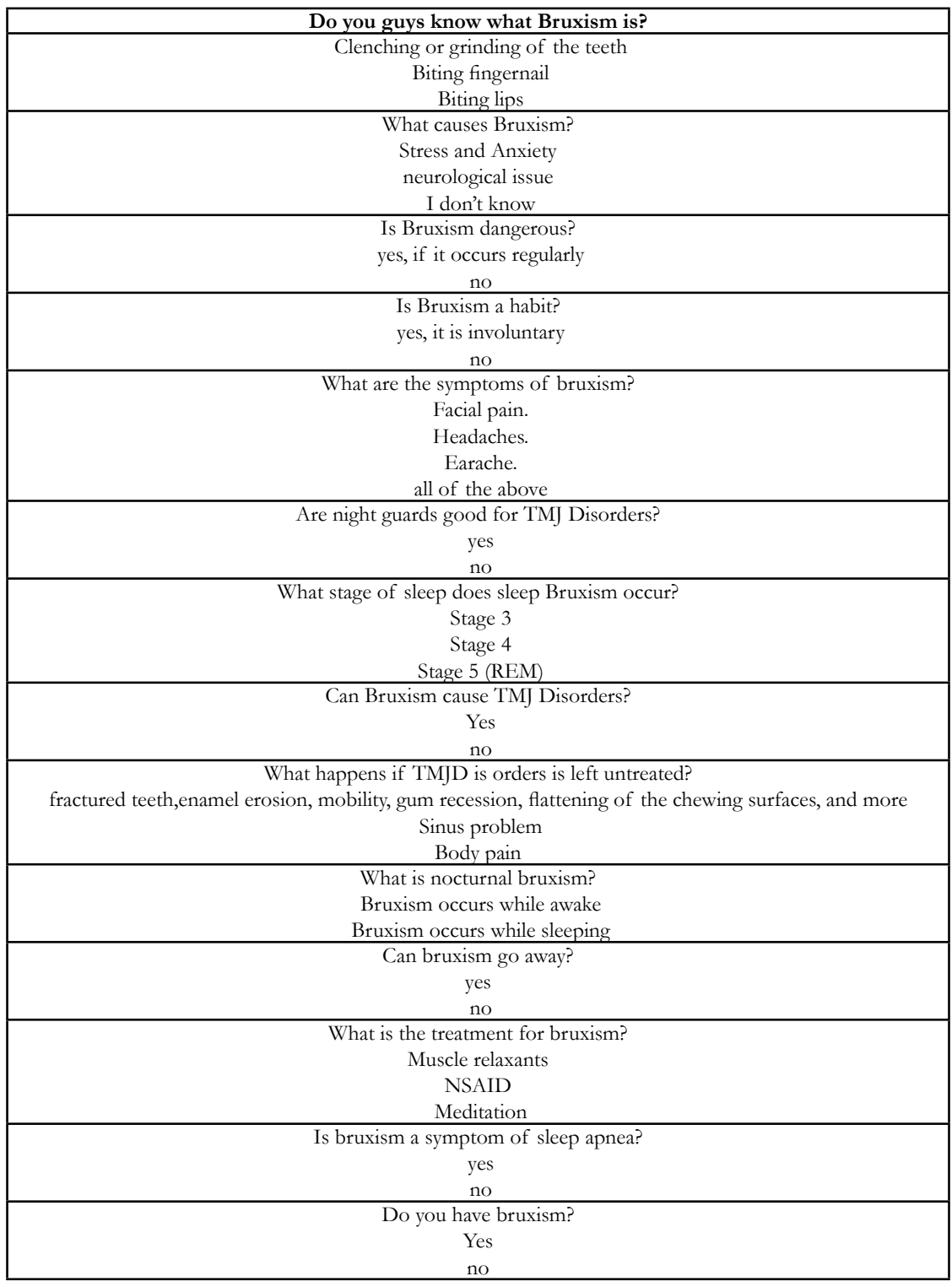


ular dysfunction. Better counselling and behavioural strategies splint theory are prescribed in order to avoid Severity. There are some limitations in the Survey study we could have increased the sample size. So that it could have reached a lot of people to help prevent it.

\section{References}

[1]. Ajay R, Suma K, Ali SA, Kumar Sivakumar JS, Rakshagan V, Devaki V, et al. Effect of Surface Modifications on the Retention of Cement-retained Implant Crowns under Fatigue Loads: An In vitro Study. J Pharm Bioallied Sci. 2017 Nov;9(Suppl 1):S154-S160. Pubmed PMID: 29284956.

[2]. Jain AR, Nallaswamy D, Ariga P, Ganapathy DM. Determination of correlation of width of maxillary anterior teeth using extraoral and intraoral factors in Indian population: A systematic review. World J Dent. 2018 Jan;9:68-75.

[3]. Ashok V, Nallaswamy D, Benazir Begum S, Nesappan T. Lip Bumper Prosthesis for an Acromegaly Patient: A Clinical Report. J Indian Prosthodont Soc. 2014 Dec;14(Suppl 1):279-82. Pubmed PMID: 26199531.

[4]. Ashok V, Suvitha S. Awareness of all ceramic restoration in rural population. Research Journal of Pharmacy and Technology. 2016 Oct 28;9(10):1691-3.

[5]. Bader G, Lavigne G. Sleep bruxism; an overview of an oromandibular sleep movement disorder. Sleep medicine reviews. 2000 Feb 1;4(1):27-43.

[6]. Basha FY, Ganapathy D, Venugopalan S. Oral hygiene status among pregnant women. Research Journal of Pharmacy and Technology. 2018 Jul 31;11(7):3099-102.

[7]. Berger M, Litko M, Ginszt M, Alharby H, Szkutnik J, Majcher P, et al. Use of common stimulants and awake bruxism-a survey study. Polish Journal of Public Health. 2016 Sep 1;126(3):130-3.

[8]. CawsonRA, Odell EW, PorterSR. Cawson's Essentials of Oral Pathology and Oral Medicine. Churchill Livingstone.2002.

[9]. Commisso MS, Martínez-Reina J, Mayo J. A study of the temporomandibular joint during bruxism. International Journal of Oral Science. 2014 Jun;6(2):116-23.

[10]. Demjaha G, Kapusevska B, Pejkovska-Shahpaska B. Bruxism Unconscious Oral Habit in Everyday Life. Open Access Maced J Med Sci. 2019 Mar 14;7(5):876-881. Pubmed PMID: 30962854.

[11]. Detamore MS, Athanasiou KA. Structure and function of the temporomandibular joint disc: implications for tissue engineering. J Oral Maxillofac Surg. 2003 Apr;61(4):494-506. Pubmed PMID: 12684970

[12]. Duraisamy R, Krishnan CS, Ramasubramanian H, Sampathkumar J, Mariappan S, NavarasampattiSivaprakasam A. Compatibility of Nonoriginal Abutments With Implants: Evaluation of Microgap at the Implant-Abutment Interface, With Original and Nonoriginal Abutments. Implant Dent. 2019 Jun;28(3):289-295. Pubmed PMID: 31124826.

[13]. Fernandes G, Franco AL, Siqueira JT, Gonçalves DA, Camparis CM. Sleep bruxism increases the risk for painful temporomandibular disorder, depression and non-specific physical symptoms. J Oral Rehabil. 2012 Jul;39(7):538-44. Pubmed PMID: 22506562.

[14]. Ganapathy D, Sathyamoorthy A, Ranganathan H, Murthykumar K. Effect of Resin Bonded Luting Agents Influencing Marginal Discrepancy in All Ceramic Complete Veneer Crowns. J ClinDiagn Res. 2016 Dec;10(12):ZC67ZC70. Pubmed PMID: 28209008.

[15]. Ganapathy DM, Kannan A, Venugopalan S. Effect of coated surfaces influencing screw loosening in implants: A systematic review and meta-analysis. World Journal of Dentistry. 2017 Nov;8(6):496-502.
[16]. Huang GJ, LeResche L, Critchlow CW, Martin MD, Drangsholt MT. Risk factors for diagnostic subgroups of painful temporomandibular disorders (TMD). Journal of dental research. $2002 \mathrm{Apr} ; 81(4): 284-8$.

[17]. Ranganathan H, Ganapathy DM, Jain AR. Cervical and Incisal Marginal Discrepancy in Ceramic Laminate Veneering Materials: A SEM Analysis. ContempClin Dent. 2017 Apr-Jun;8(2):272-278. Pubmed PMID: 28839415.

[18]. Jyothi S, Robin PK, Ganapathy D. Periodontal health status of three different groups wearing temporary partial denture. Research Journal of Pharmacy and Technology. 2017 Dec 1;10(12):4339-42.

[19]. Kannan A, Venugopalan S. A systematic review on the effect of use of impregnated retraction cords on gingiva. Research Journal of Pharmacy and Technology. 2018 May 30;11(5):2121-6.

[20]. Kundu, A. 'Bruxism (Teeth Grinding)', Pearls in Medicine for Students.2008; 35-35. doi: 10.5005/jp/books/10593_11.

[21]. Lavigne GJ, Khoury S, Abe S, Yamaguchi T, Raphael K. Bruxism physiology and pathology: an overview for clinicians. J Oral Rehabil. 2008 Jul;35(7):476-94. Pubmed PMID: 18557915.

[22]. Manfredini D, Serra-Negra J, Carboncini F, Lobbezoo F. Current Concepts of Bruxism. Int J Prosthodont. 2017 September/October;30(5):437-438. Pubmed PMID: 28806429.

[23]. Manfredini D. The Triangle Bruxism, Pain, and Psychosocial Factors. University of Amsterdam.2011.

[24]. Manfredini D, Winocur E, Guarda-Nardini L, Paesani D, Lobbezoo F. Epidemiology of bruxism in adults: a systematic review of the literature. J Orofac Pain. 2013 Spring;27(2):99-110. Pubmed PMID: 23630682.

[25]. Orlova, O. (no date) 'Botulinum Toxin Therapy for Bruxism', Treatment of Dystonia, pp. 182-184. doi: 10.1017/9781316459324.038.

[26]. Radin EL, Martin RB, Burr DB, Caterson B, Boyd RD, Goodwin C. Effects of mechanical loading on the tissues of the rabbit knee. Journal of orthopaedic research. 1984;2(3):221-34.

[27]. Scully C, Kalantzis A. Oxford handbook of dental patient care. Oxford University Press, USA; 2005.

[28]. Selvan SR, Ganapathy D. Efficacy of fifth generation cephalosporins against methicillin-resistant Staphylococcus aureus-A review. Research Journal of Pharmacy and Technology. 2016 Oct 28;9(10):1815-8.

[29]. Shetty S, Pitti V, Babu CS, Kumar GS, Deepthi BC. Bruxism: a literature review. The Journal of Indian Prosthodontic Society. 2010 Sep;10(3):141-8.

[30]. Stratmann U, Schaarschmidt K, Santamaria P. Morphometric investigation of condylar cartilage and disc thickness in the human temporomandibular joint: significance for the definition of ostearthrotic changes. J Oral Pathol Med. 1996 May;25(5):200-5. Pubmed PMID: 8835815.

[31]. Subasree S, Murthykumar K. Effect of aloe vera in oral health-A review. Research Journal of Pharmacy and Technology. 2016 May 1;9(5):609.

[32]. Thompson RC Jr, Oegema TR Jr, Lewis JL, Wallace L. Osteoarthrotic changes after acute transarticular load. An animal model. J Bone Joint Surg Am. 1991 Aug;73(7):990-1001. Pubmed PMID: 1714911.

[33]. Venugopalan S, Ariga P, Aggarwal P, Viswanath A. Magnetically retained silicone facial prosthesis. Niger J ClinPract. 2014 Mar-Apr;17(2):260-4. Pubmed PMID: 24553044.

[34]. Vijayalakshmi B, Ganapathy D. Medical management of cellulitis. Research Journal of Pharmacy and Technology. 2016 Nov 28;9(11):2067-70.

[35]. Yap AU, Chua AP. Sleep bruxism: Current knowledge and contemporary management. Journal of conservative dentistry: JCD. 2016 Sep;19(5):383.

[36]. YoungN, BlitzerA. 'Treatment of Oromandibular Dystonia, Bruxism, and Temporomandibular Disorders with Botulinum Toxin', Botulinum Toxin.2009; 204-213. doi: 10.1016/b978-1-4160-4928-9.00016-0. 
